\title{
Scattering light in bearing production: roundness, waviness, roughness in one operation
}

\section{Stephan Sommer, Boris Brodmann, Dominik Helfrich}

Stephan Sommer, Boris Brodmann, Dominik Helfrich, "Scattering light in bearing production: roundness, waviness, roughness in one operation," Proc. SPIE 11144, Photonics and Education in Measurement Science 2019, 111440G (17 September 2019); doi: 10.1117/12.2531566

SPIE Event: Joint TC1 - TC2 International Symposium on Photonics and Education in Measurement Science 2019, 2019, Jena, Germany 


\title{
Scattering light in bearing production: roundness, waviness and roughness in one operation
}

\author{
Stephan Sommer, Hochschule Würzburg-Schweinfurt, Schweinfurt, stephan.sommer@fhws.de \\ Boris Brodmann, OptoSurf GmbH, Ettlingen, b.brodmann@optosurf.de \\ Dominik Helfrich, Steinbeis Transferzentrum Wälzlagertechnik, Herzogenaurach, \\ dominik.helfrich@stw.de
}

\begin{abstract}
Bearings are precision machine elements with very high requirements regarding the roundness, waviness and roughness of the rolling elements as well as the bearing rings. The production processes have to meet sub-micron tolerances. To verify production quality, state of the art tactile measuring technologies are used, such as roundness and waviness measurements as well as roughness measurement according to ISO 4287 [3]. To measure roundness and waviness a special gauge is used, where as a second gauge is measuring the roughness of the surface. The measurements are mostly performed in a laboratory environment checking parts in a random sampling procedure. To meet the rising demands on quality of bearings, it is necessary to increase the sample size. On the other hand, this increases the time needed for quality inspection. The optical measuring technology SCATTERING LIGHT can help to solve these contradictory demands. The technology is based on the reflection of light from a surface. It can be used to measure roundness, waviness and roughness in one single operation. Providing a clean environment, the measurements with scattering light can be automated and integrated in production processes such as honing and grinding. Furthermore, the cycle time is shorter than from the tactile measuring procedure. Results from scattering light measurements can be calibrated. Roundness and waviness are traceable to international standards. The optical result for surface roughness "Aq" is a new parameter that does not correlate to the common known Ra and Rz values but to the occasionally used Rdq value.
\end{abstract}

Keywords: Bearings, roundness, waviness, roughness, scattering light, ISO 4287, tactile measurement, surface quality

\section{FUNDAMENTALS OF SCATTERING LIGHT TECHNOLOGY}
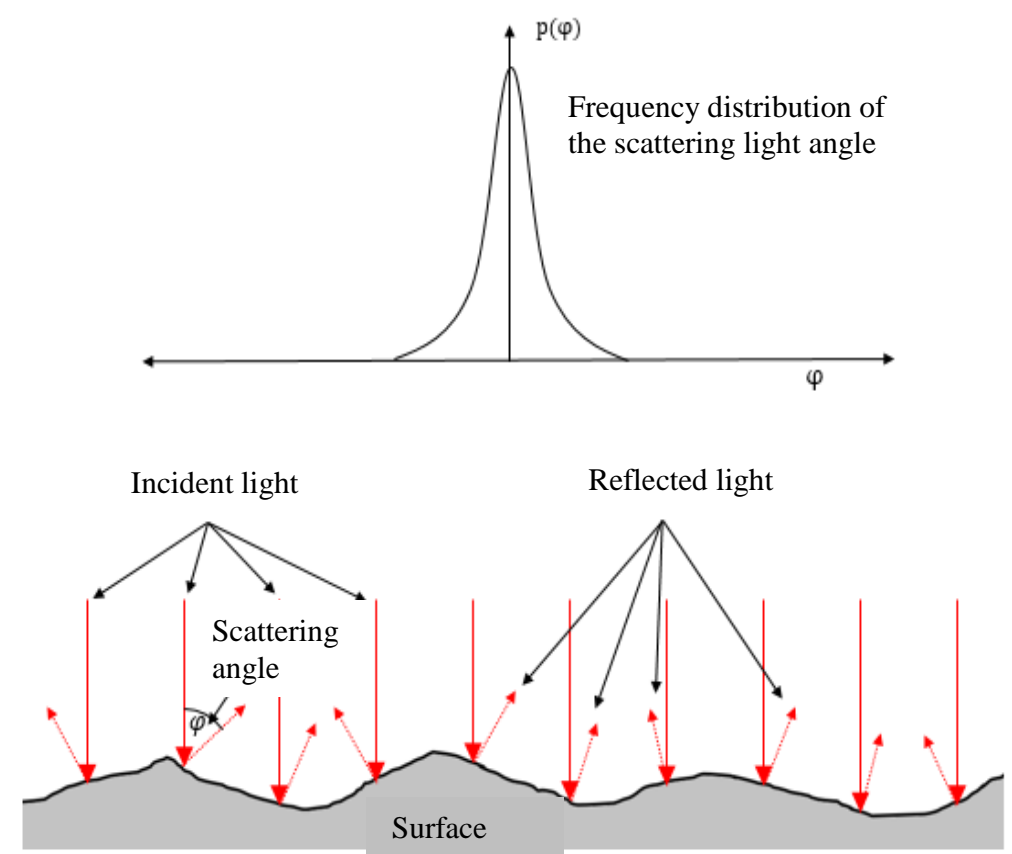

Figure 1: Angle distribution and micro profile angle of a rough surface
The scattering light technology is an alternative measuring method to detect the micro-geometry of technical surfaces. It is defined by VDA 2009 [6]. This guideline describes the angular resolution measuring method of scattering light. This method is particularly suitable for smooth surfaces, which require a very low coefficient of friction [5]. The measuring method is based on the law of light scattering and the model of mirror facets. Figure 1 shows the concept of the scattering light method. Incident light is reflected by the micro profile angles $\varphi$ of a rough surface [6]. By means of a Fourier optic the reflected light is transmitted in a focal plane. A detector records the intensity distribution, which equals the frequency distribution of the scattering angle. 
Figure 2 shows the relations of the mirror facet. The geometry of the facet is characterized by the angle $\theta$ or the gradient $\mathrm{dz} / \mathrm{dx}$. Geometrical optics allow the application of the law of reflection as shown in figure 2. The profile edges of technical surfaces do not have a high gradient, therefore it can be assumed that

$\frac{\partial z}{\partial x} \approx \theta$

The scattering angle $\varphi$ is

$\varphi=2 \theta$

and the variance of the angular distribution shown in figure 2 can be calculated, as in VDA 2009 [6] defined, as the parameter Aq.

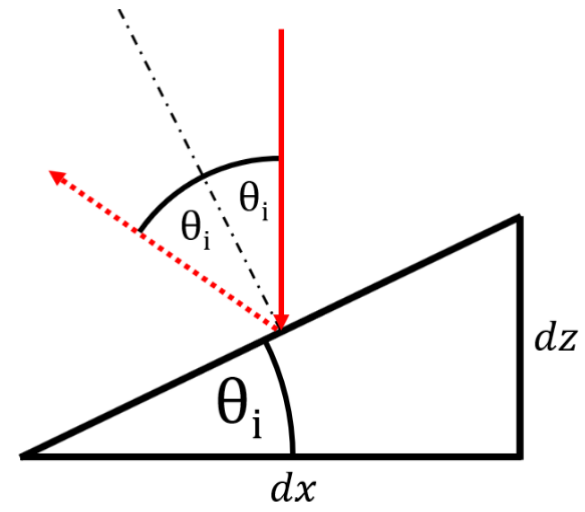

Figure 2: $\quad$ Mirror facet $A q=k \cdot \sum_{i=1}^{n}\left(2 \theta_{i}-2 \bar{\theta}\right)^{2} \cdot p\left(2 \theta_{i}\right)$

$\bar{\theta}$ equals the first statistical moment and the mean scattering angle of the bundle of rays. $p\left(2 \theta_{i}\right)$ states the standardized single probability of one angle class. Figure 3 shows the standardized distributions of the surfaces "honed" and "multiple honed". Using (3) for the calculation of the Aq-value we are receiving an Aq $=3,80$ for the multiple honed surface and $\mathrm{Aq}=30,33$ for the single honed surface. The counter measurement with a confocal microscope shows a significant correlation.
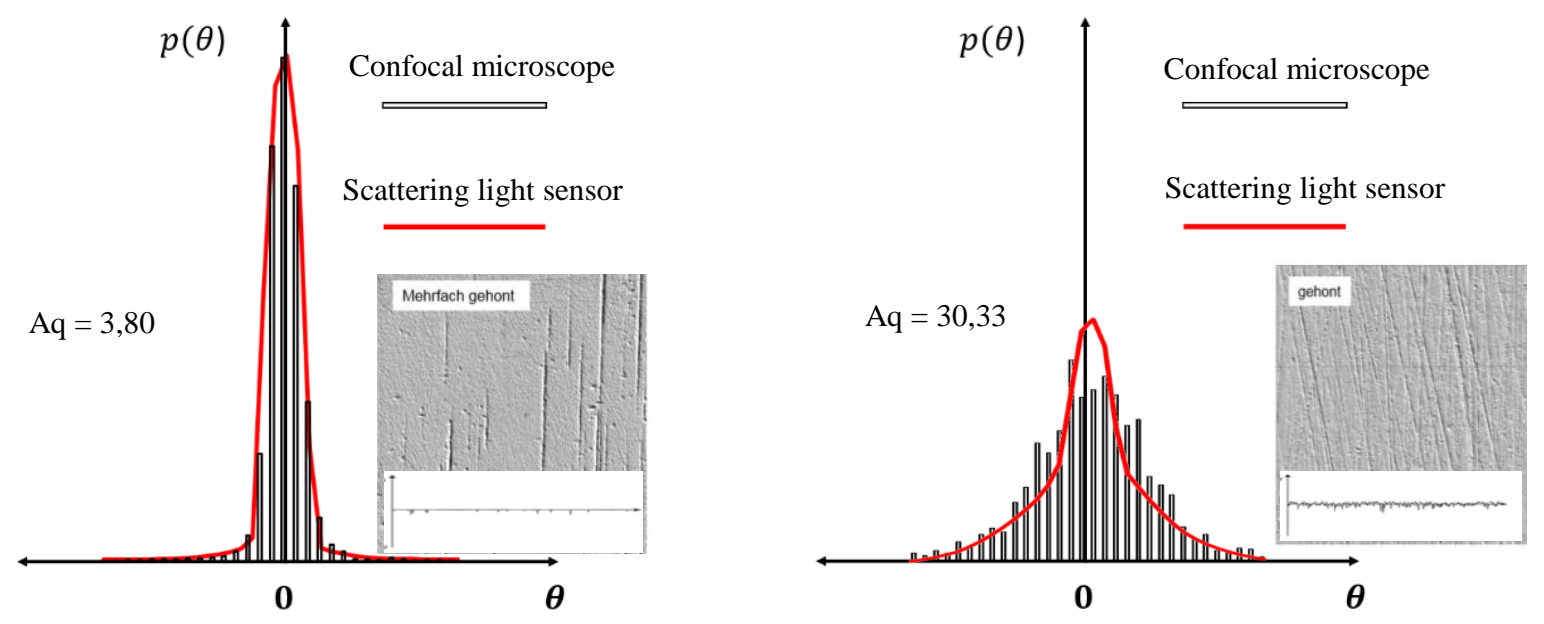

Figure 3:Comparison of scattering light and confocal measurements on honed and multiple honed surfaces

It is necessary for the calculation of the gradient distribution of the roughness profile to use a $\lambda$ s-low-pass-filter. Additionally, the lateral resolution of the measuring instrument must be taken into account [2]. 
The scattering light method is also able to assess the macro geometry (form profile) of the surface. $\bar{\theta}$ represents the local gradient and is therefore the derivation of the form profile. Figure 4 shows a comparison between two form profile measurements. On the left-hand side is the optical measurement and on the right-hand side the tactile measurement. The correlation of these two measurement methods is obvious.

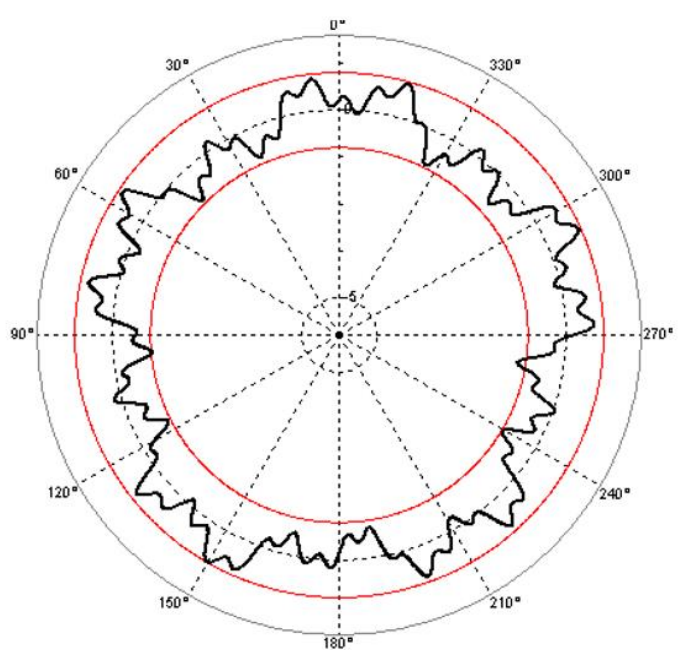

Optical measurement

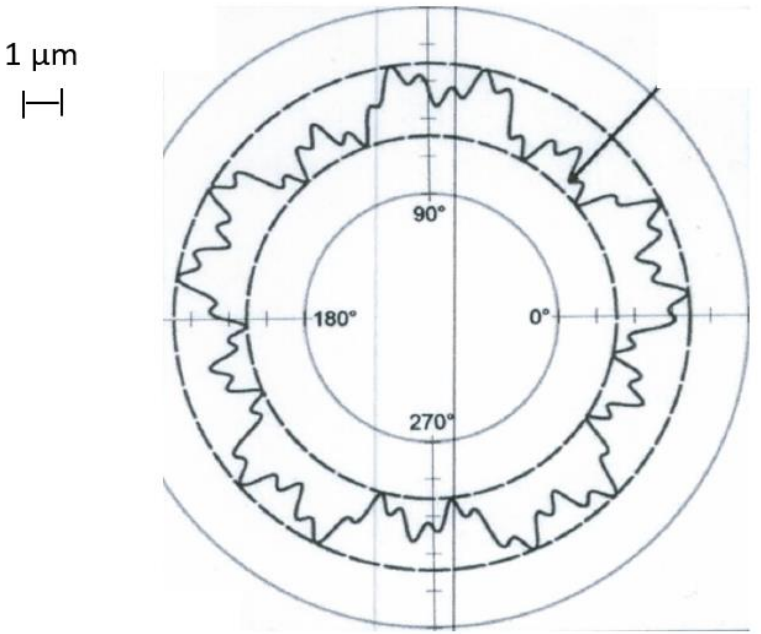

Tactile measurement

Figure 4:Comparison of scattering light (left) and tactile measurement of the form profile

\section{FOURIER ANALYSIS OF THE FORM PROFILE TO ASSESS THE ACOUSTICAL CHARACTERISTICS}

For the prediction of the noise properties, due to harmonic excitation of the bearing, an analysis of the form profile by the means of a Fourier analysis is suitable. The idea is that the rolling ball of the ring surface is stimulating the bearing to oscillate. The excitation of the bearing can be distinguished as a broadband or a harmonic excitation. The harmonic excitation is more unpleasant, because it creates a single tone, which can change during the modulation [1].

Usually the roller bearing industry measures the shape and waviness in a precision measurement room under ideal conditions with a form tester. The application in production environment is not advisable, because ambient vibrations distort the measurement results. These distorted measurements can easily lead to expensive misinterpretation. Figure 5 shows a form profile of a ground inner ring with a maximal deviation of roundness of $1,88 \mu \mathrm{m}$. This is mainly driven by the long-wave parts [7]. For the determination of the roundness or $\Delta \mathrm{r}$ a low-pass filter is used. This filter eliminates the high frequency components (waviness and roughness). 

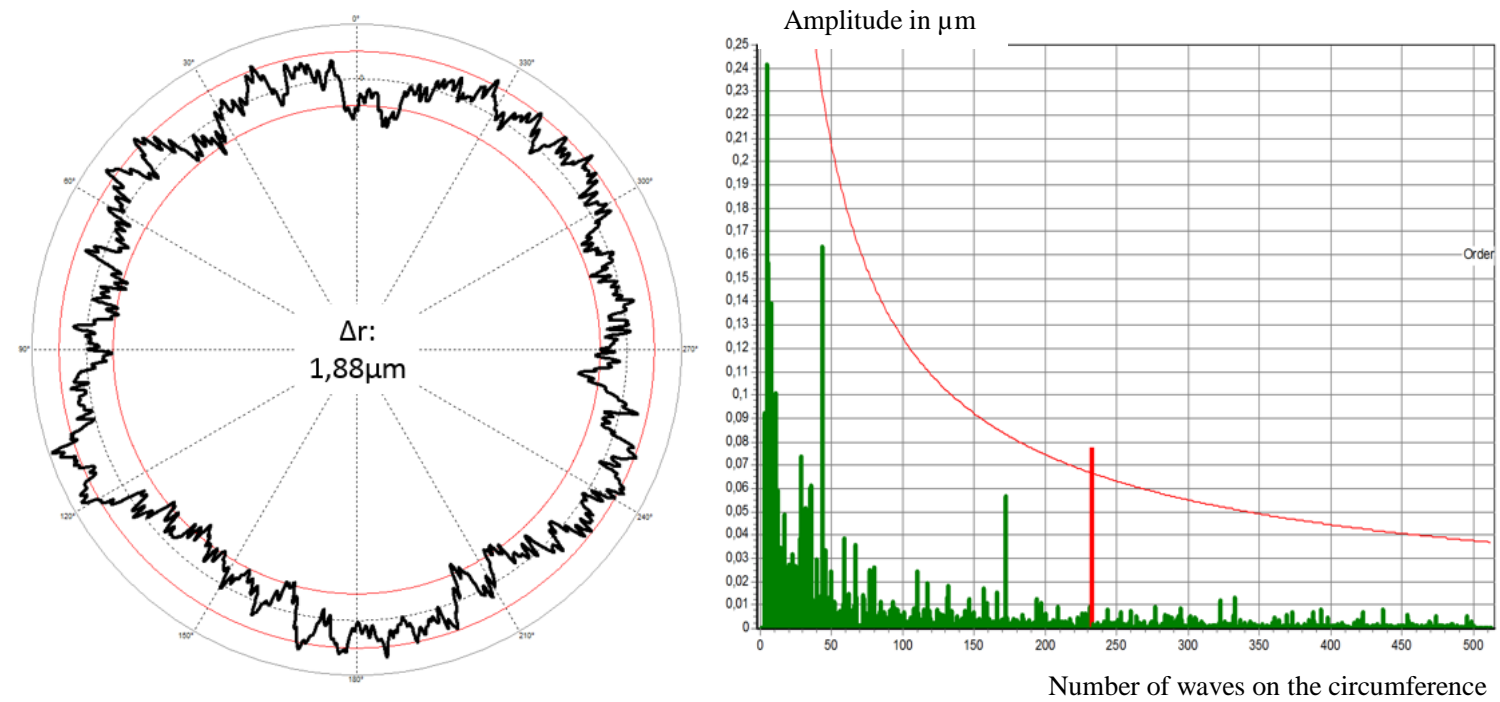

Figure 5: Polar diagram and amplitude spectrum of a ground inner ring

To evaluate the high frequency parts, the form profile undergoes a FFT (Fast Fourier Transformation). Figure 5 shows a significant peak at wave number 233 (233 waves/ circumference). The absolute amplitude is just $0,075 \mu \mathrm{m}$, but this leads to an acoustic abnormality of the bearing. The frequencies in the medium and high frequency range ( $>25$ waves/ circumference) are often the reason for complaints regarding the noise [1].

Honing (finishing [4]) leads to an optimization of the finish, a better roughness, improvement of the absolute form deviation and a reduction of the amplitudes in the frequency spectrum, as shown in figure 6. On this account, the Fourier analysis of the form profile is a standard process in the quality assurance.
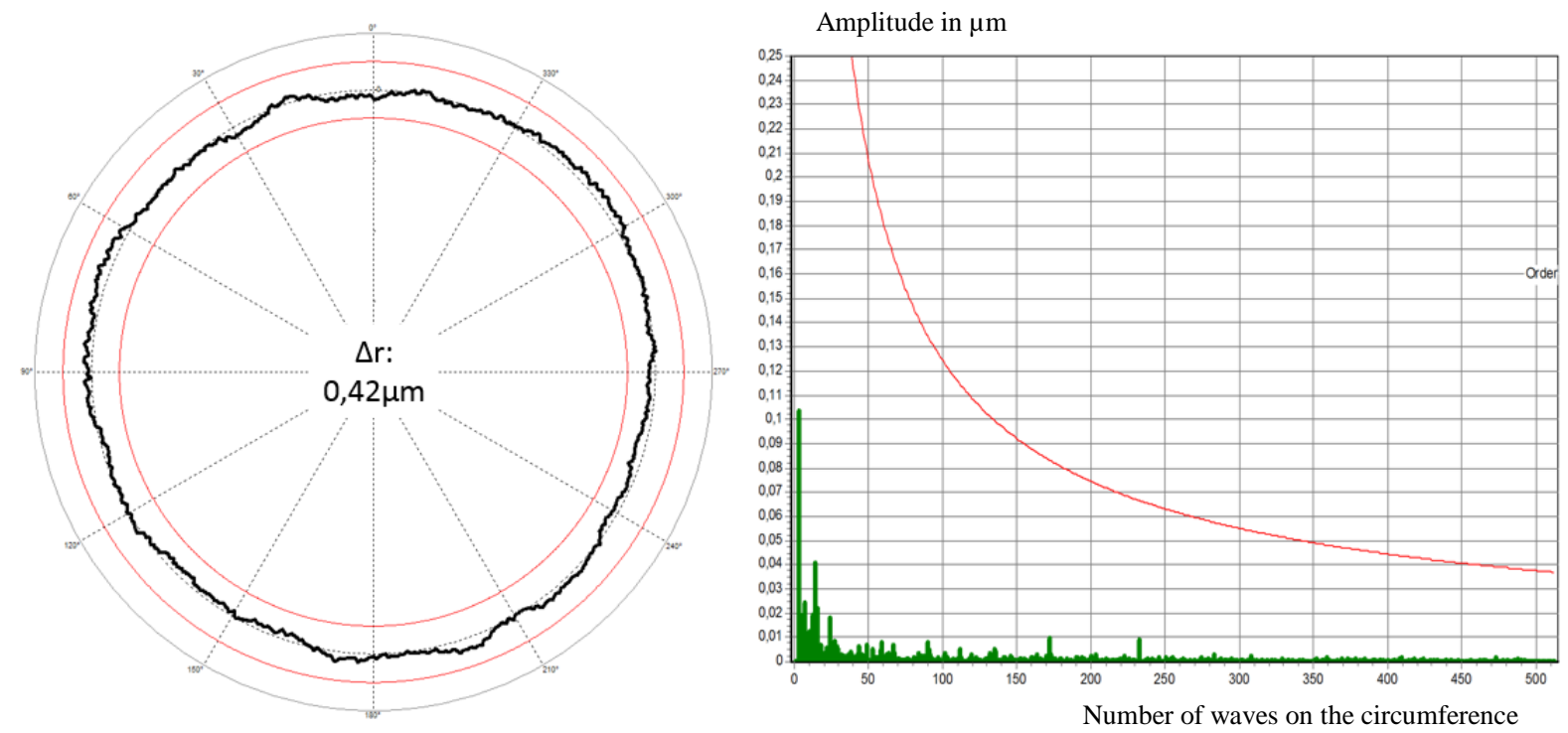

Figure 6. Polar diagram and amplitude spectrum of a honed inner ring 


\section{APPLICATION OF THE SCATTERING LIGHT TECHNOLOGY IN THE BEARING INDUSTRY}

\section{$3.1100 \%$ measurement of bearing rings}

The quality assurance in the production of bearings requires precision measurements. It is the aim to meet tightest tolerances at large quantities and short cycle times. Due to the high afford of lab measurements, e.g. long walking distances to the lab and long measuring durations, traditional measuring methods are only capable of measuring samples to monitor the process capability. Random errors in the production process can easily be overlooked. Therefor a $100 \%$ in-line process monitoring would be a major advantage. Figure 7 shows the scattering light sensor in a line integrated testing machine for a 100\% monitoring of the raceways from outer rings. Form, waviness and roughness of the raceway

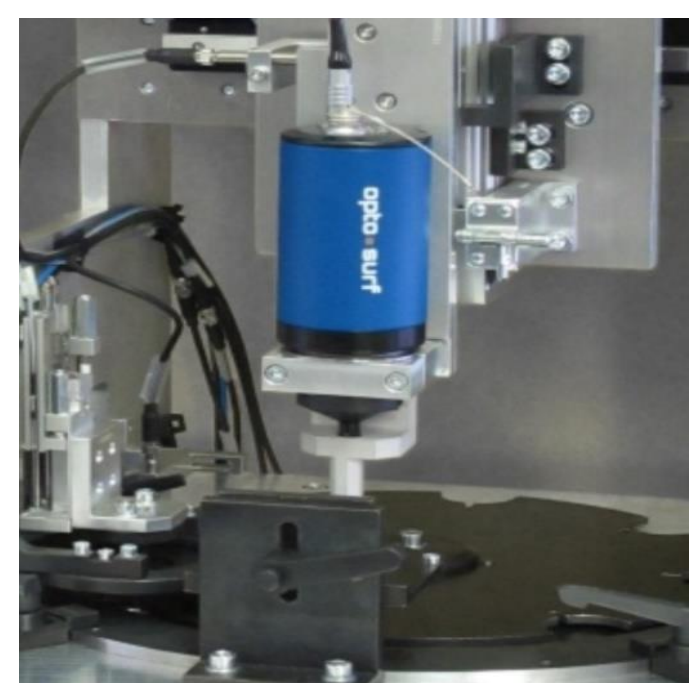

Figure 7: Testing machine with scattering light is measured with a scattering light sensor. Figure 8 shows typical failures, which can occur in the serial production of ball bearings. The figure 8 shows an example of an incompletely honed raceway.
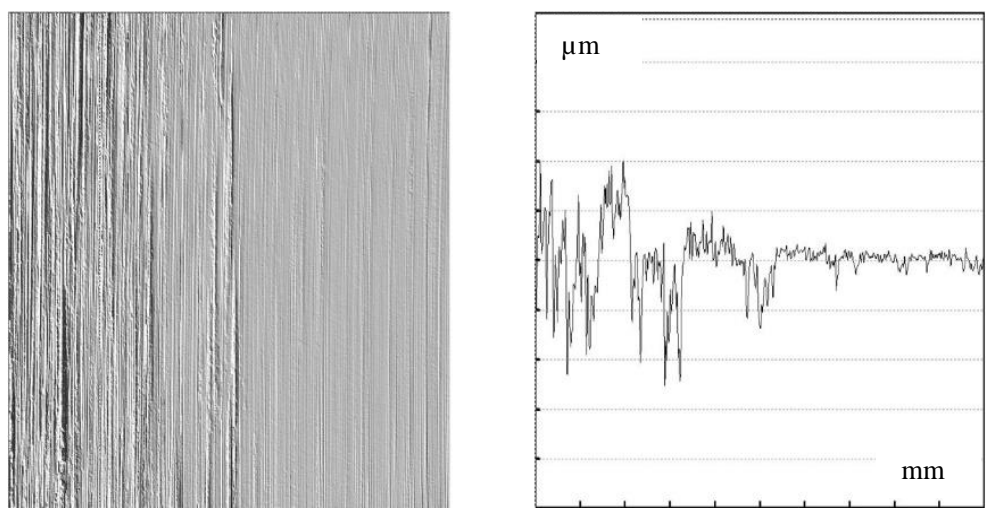

Figure 8:

Example of an incompletely honed raceway

If these errors are located in the contact area of the rolling elements, it is likely that the bearing will be noisy in its future operation. With random sampling inspection, these errors can only be found by chance.

Figure 9 shows the measuring setup of the scattering light. 1024 overlapping measuring points of the scattering light are distributed around the circumference. Well-honed surfaces show Aq values between the red tolerance borders in the diagrams. Ground rings show Aq values, which are significant over the tolerance. Local areas, which are poorly honed, can be detected easily. Similar results are received, when the form of the ring is evaluated. Figure 10 shows a diagram of the roundness and an amplitude spectrum of the roundness profile of an incompletely honed bearing ring. You can see local waviness in the roundness profile in the area of the grinding finish. The amplitude spectrum also shows this error, therefore a decreasing tolerance curve in the $100 \%$ inspection evaluates the ring as defect and sorts the part out. The testing machine, which is shown in figure 11, needs less than one second for the measurement and the evaluation of a ring. Mandatory requirement for the measurements is a clean surface. Even though a separate washing process is not necessarily needed, because a thin and homogeneous distributed oil film on the surface does not affect the measurement. 
Results of scattering light measurements
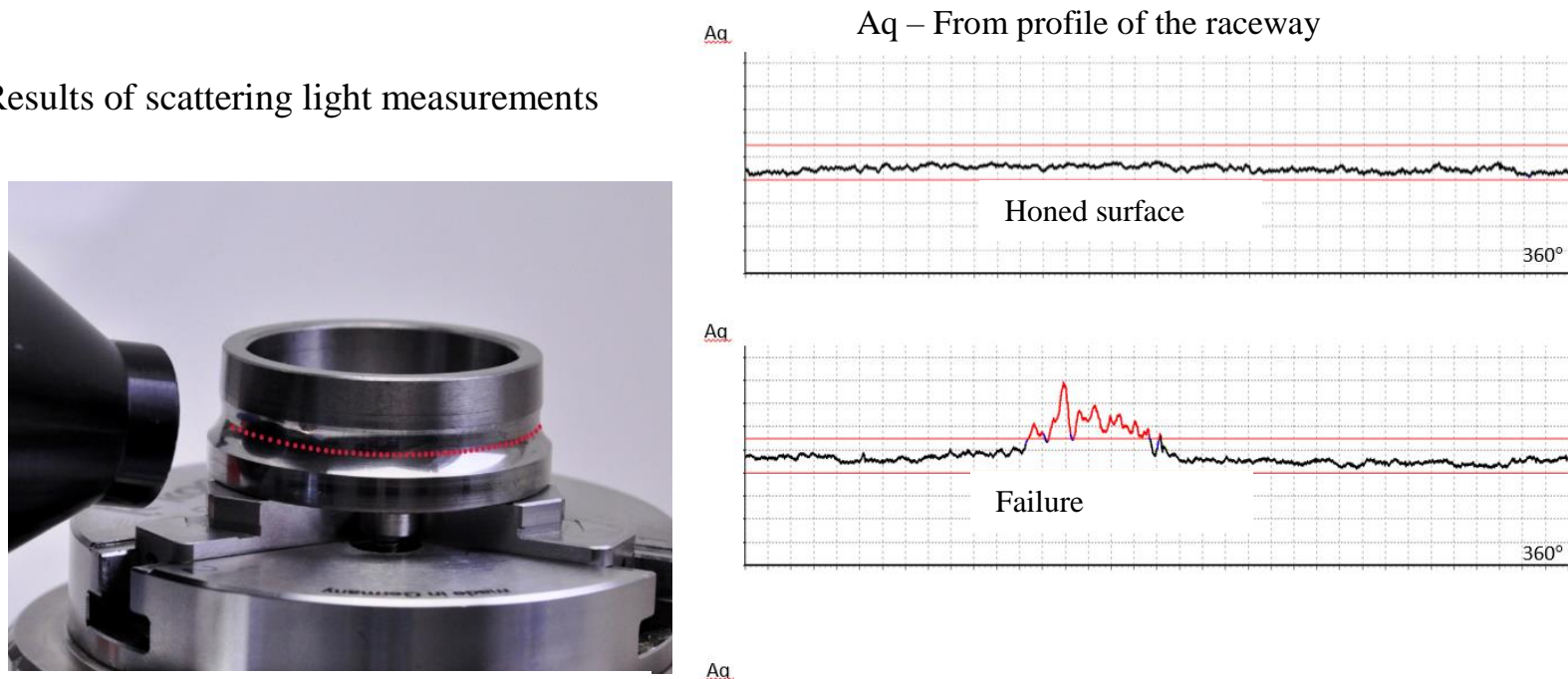

$\mathrm{Aq}$

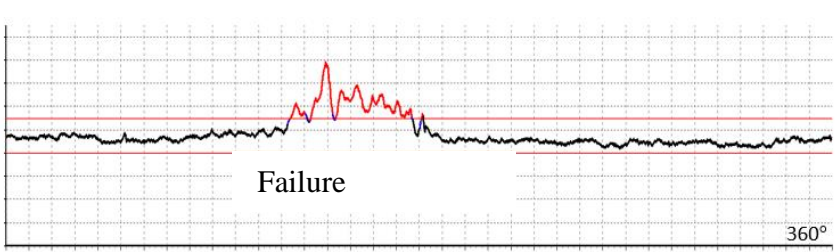

$\mathrm{Aa}$

1024 overlapping measuring points on the circumference of a bearing ring

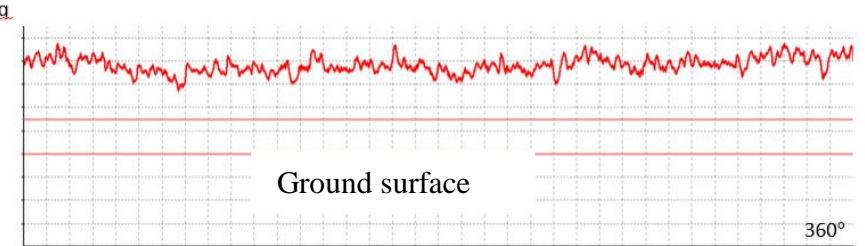

Figure 9: Measurement setup inner ring with scattering light. (Left), Aq-profiles of an incompletely honed and ground raceway
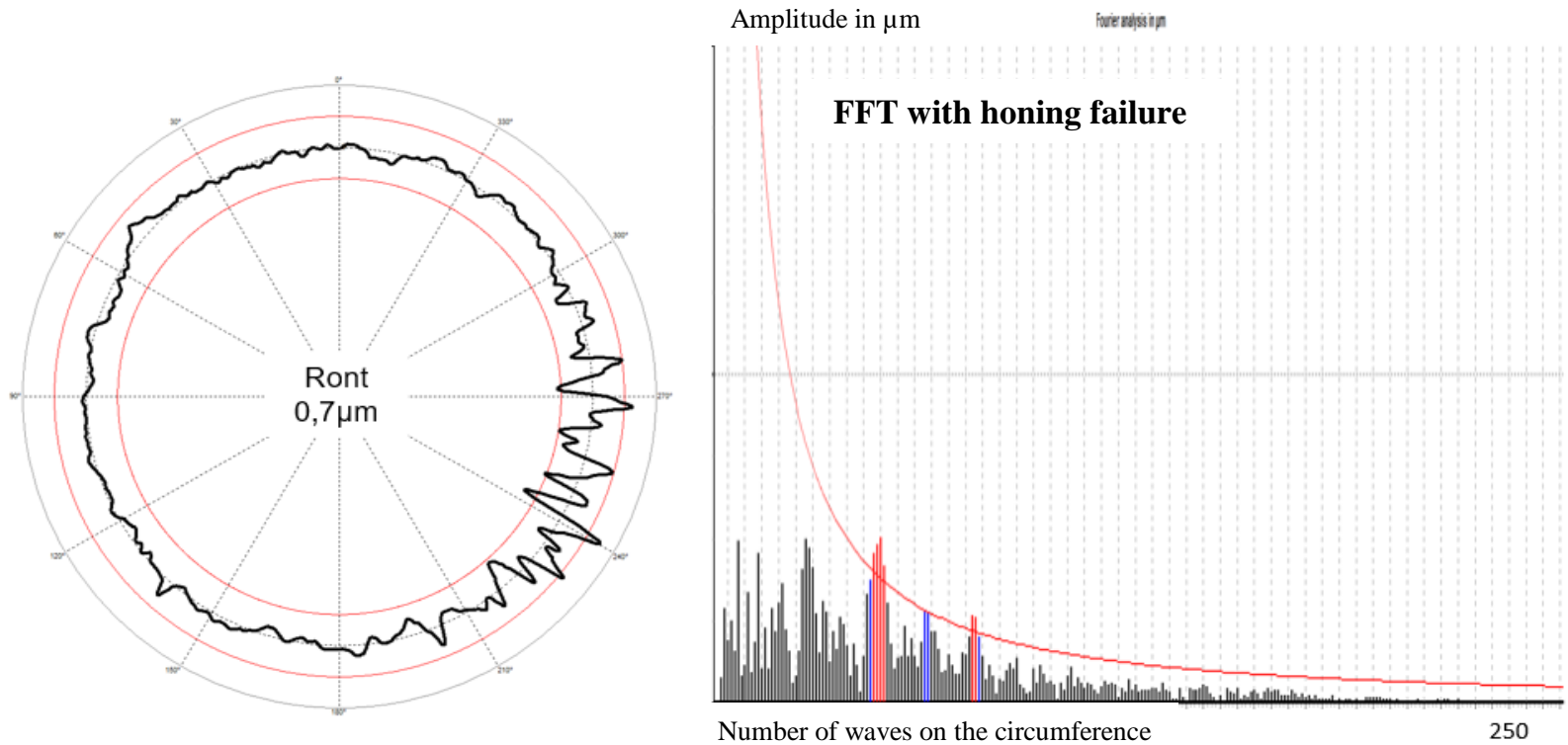

Figure 10: Roundness profile and FFT of an incompletely honed inner ring 


\subsection{Measuring the waviness of the raceways on a ball screw drive}

Nowadays, ball screws drives are components in electronic power steering of cars. The quality of the surface of the raceway has a crucial importance for the noise behavior of the steering. The waviness of the raceway in the contact zone of ball and ring is of vital importance. A finishing process eliminates the waviness, which is usually created in previous processes. A big challenge hereby is the various performance of the bearing in operation. If the finishing process is done only unilateral, a useful evaluation with coordinate measurement is not possible, because measurement takes place on both edges. The scattering light is capable to swing the sensor and to explicitly assign the waviness to both edges of the raceway. Figure 11 shows the measurement setup for the ball screw drive [7].

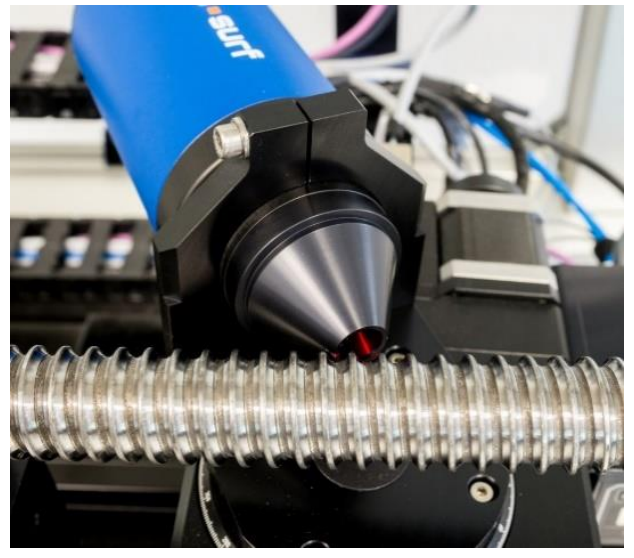

Figure 11: Measuring the waviness of a ball screw drive

\section{SUMMARY}

The automotive industry has an increasing demand in the quality of rolling bearings. Tolerances in roughness and waviness shift to sub micrometers. Statistical values of amplitude distribution and angle distribution are very capable of describing the roughness of surfaces. Whereas, induced waviness can be found in the amplitude spectrum of the Fourier analysis of the form profile. The scattering light provides a traceable measurement technology, which calculates the statistical roughness value Aq. The scattering light can distinguish different manufacturing processes such as honing and grinding. Simultaneously, the macro gradient of the form profile can be determined with the integration of the form profile. This technology is robust, fast, non-contact and can be used in manufacturing areas for a 100\% -monitoring of the production process. 


\section{REFERENCE LINKING}

Website: $\quad$ www.optosurf.de

WwW.steinbeis-waelzlagertechnik.de

Labor für Qualitätsmanagement und Fertigungsmesstechnik

https://fm.fhws.de/fakultaet/laboratorien/labor_fertigungstechnisch_messen.html

YouTube: $\quad$ Labor für Fertigungsmess- und Wälzlagertechnik

https://www.youtube.com/channel/UCI1gpsJzABG8xURdCbnbJjg

\section{REFERENCES}

[1] Hutzler, M.: Anwendung der harmonischen Analyse in der Wälzlagerfertigung, VDI Wissensforum, 2016

[2] Bodschwinna, H.: Oberflächenmeßtechnik zur Beurteilung und Optimierung technischer Funktionsflächen, Aachen, Shaker Verlag, 2000

[3] ISO 4287: Geometrical Product Specifications (GPS) - Surface texture: Profile method - Terms, definitions and surface texture parameters, Berlin Beuth Verlag 2010

[4] Riedel, W. Kurbelwellenfinish mit engsten Lagerabständen, Velbert, Schleifen und Polieren 6/2017

[5] Brodmann, R., Allgäuer, M.: Comparison of light scattering from rough surfaces with optical and mechanical profilometry in surface measurement and characterization. In: Proc. SPIE, vol. 1009, pp. 111-118 (1988)

[6] VDA2009 Geometrishe Produktspezifikation, Winkelaufgelöste Streulichtmethode, Definition, Kenngrößen und Anwendung. 2010/01

[7] Brodmann, B., Helfrich, D., Sommer S.: Prozessüberwachung funktionskritischer Oberflächen in der Wälzlagerindustrie, Wälz- und Gleitlagertagung, Schweinfurt 2019 